\title{
Complete genome sequence of Rhizobium leguminosarum bv trifolii strain WSM2304, an effective microsymbiont of the South American clover Trifolium polymorphum
}

\author{
Wayne Reeve $^{1 *}$, Graham O'Hara ${ }^{1}$, Patrick Chain ${ }^{2,3}$, Julie Ardley ${ }^{1}$, Lambert Bräu ${ }^{1}$, Kemanth \\ Nandesena ${ }^{1}$, Ravi Tiwari ${ }^{1}$, Stephanie Malfatti ${ }^{2,3}$, Hajnalka Kiss ${ }^{2,3}$, Alla Lapidus ${ }^{2}$, Alex \\ Copeland", Matt Nolan², Miriam Land ${ }^{2,4}$, Natalia Ivanova ${ }^{2}$, Konstantinos Mavromatis ${ }^{2}$, \\ Victor Markowitz ${ }^{5}$, Nikos Kyrpides ${ }^{2}$, Vanessa Melino ${ }^{1}$, Matthew Denton ${ }^{6}$, Ron Yates ${ }^{1,7}$ \& \\ John Howieson ${ }^{1,7}$. \\ ${ }^{1}$ Centre for Rhizobium Studies, Murdoch University, Western Australia, Australia \\ ${ }^{2}$ DOE Joint Genome Institute, Walnut Creek, California, USA \\ ${ }^{3}$ Lawrence Livermore National Laboratory, Livermore, California, USA \\ ${ }^{4}$ Oak Ridge National Laboratory, Oak Ridge, Tennessee, USA \\ ${ }^{5}$ Biological Data Management and Technology Center, Lawrence Berkeley National \\ Laboratory, Berkeley, California, USA \\ ${ }^{6}$ Department of Primary Industries, Victoria, Australia \\ ${ }^{7}$ Department of Agriculture and Food, Western Australia, Australia
}

*Corresponding author: Wayne Reeve

Keywords: microsymbiont, non-pathogenic, aerobic, Gram-negative rod, root-nodule bacteria, nitrogen fixation, Alphaproteobacteria

Rhizobium leguminosarum bv trifolii is the effective nitrogen fixing microsymbiont of a diverse range of annual and perennial Trifolium (clover) species. Strain WSM2304 is an aerobic, motile, non-spore forming, Gram-negative rod, isolated from Trifolium polymorphum in Uruguay in 1998. This microsymbiont predominated in the perennial grasslands of Glencoe Research Station, in Uruguay, to competitively nodulate its host, and fix atmospheric nitrogen. Here we describe the basic features of WSM2304, together with the complete genome sequence, and annotation. This is the first completed genome sequence for a nitrogen fixing microsymbiont of a clover species from the American center of origin. We reveal that its genome size is $6,872,702$ bp encoding 6,643 protein-coding genes and 62 RNA only encoding genes. This multipartite genome was found to contain 5 distinct replicons; a chromosome of size 4,537,948 bp and four circular plasmids of size 1,266,105 bp, 501,946 bp, 308,747 bp and 257,956 bp.

\section{Introduction}

Since ancient times, crop fields have been regularly rotated with legumes, and this continues in the modern world because of the recognition that the productivity of agricultural systems is nitrogen dependent [1]. Legumes may redress nitrogen deficiency through the fixation of atmospheric nitrogen by rhizobia in root nodules [2]. Today, despite the ready availability of nitrogen-fertilizer manufactured through the Haber-Bosch process, globally in excess of 400 million ha of agricultural land are sustained by nitrogen derived from forage legumes [3]. These forages are grown for animal feed, for rotation with cereal crops, as disease breaks or as cover crops for tree plantations. Amongst the forage legumes, the Trifolium spp. (clovers) are acknowledged as one of the most important genera, with 237 species distributed across the temperate and sub-tropical regions of North and South America, Europe, Africa and Australasia [4].

These clovers are nodulated by $R$. leguminosarum bv trifolii, which is one of the most exploited species of root-nodule bacteria in world agriculture. However, because clovers are geographically 
Reeve et al.

widely distributed, and phenologically variable (they may be either annual [e.g. T. subterraneum] or perennial [e.g. T. pratense, T. raepens and T. polymorphum]), it is rare that a single strain of $R$. leguminosarum bv trifolii can effectively fix nitrogen across a wide diversity of clovers, especially those from different geographical and phenological backgrounds [5].

Rhizobium leguminosarum bv trifolii strain WSM2304 was isolated from a nodule recovered from the roots of the perennial clover Trifolium polymorphum growing at Glencoe Research Station near Tacuarembó, Uruguay in December 1998. WSM2304 is of particular interest because it is a highly effective microsymbiont of a perennial clover of South American origin, has a narrow, specialized host range for nitrogen fixation [5], and is highly competitive for nodulation of T. polymorphum in the acid, infertile soils of Uruguay
[6]. WSM2304 has also been implicated in host mediated selection for an effective microsymbiont under competitive conditions for nodulation [7].

Here we present a summary classification and a set of features for $R$. leguminosarum bv trifolii strain WSM2304 (Table 1), together with the description of the complete genome sequence and annotation.

\section{Classification and features}

R. leguminosarum bv trifolii strain WSM2304 is a motile, Gram-negative, non-spore-forming rod (Figure 1 A \& B) in the Rhizobiaceae family of the class Alphaproteobacteria that forms mildly mucoid colonies (Figure 1C) on solid media [24]. It has a mean generation time of $3.5 \mathrm{~h}$ in rich medium at the optimal growth temperature of $28^{\circ} \mathrm{C}$ [7].
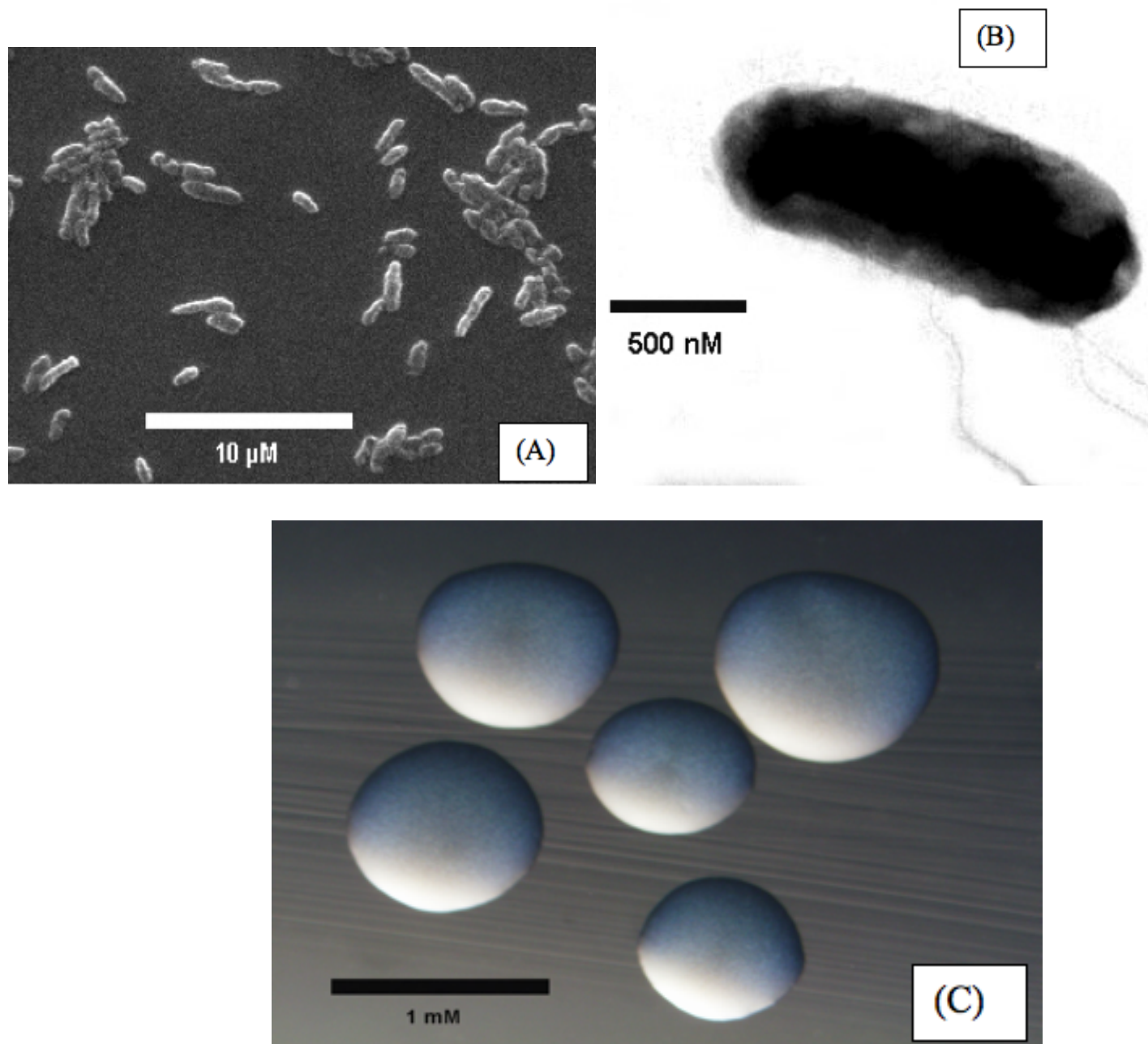

Figure 1. Images of R. leguminosarum bv trifolii strain WSM2304 using scanning (A) and transmission electron microscopy (B). The appearance of colony morphology on solid media (C). 
Figure 2 shows the phylogenetic neighborhood of R. leguminosarum bv trifolii strain WSM2304 in a 16S rRNA-based tree. An intragenic fragment of $1,440 \mathrm{bp}$ was chosen since the $16 \mathrm{~S}$ rRNA gene has not been completely sequenced in many type strains. A comparison of the entire 16S rRNA gene of WSM2304 to completely sequenced 16S rRNA genes of other rhizobia revealed $100 \%$ gene sequence identity with $R$. leguminosarum bv trifolii strain WSM1325 but a $1 \mathrm{bp}$ difference from the 16S rRNA gene of $R$. leguminosarum bv viciae strain 3841.

\section{Symbiotaxonomy}

R. leguminosarum bv trifolii WSM2304 nodulates $\left(\mathrm{Nod}^{+}\right)$and fixes nitrogen effectively $\left(\mathrm{Fix}^{+}\right)$with the South American perennial clover T. polymorphum [5]. WSM2304 is Nod', Fix- with Mediterranean annual clovers T. subterraneum and T. glanduliferum, in contrast to $R$. leguminosarum bv trifolii WSM1325 $[5,29]$. When inoculated onto perennial clovers of either North American or Mediterranean origin WSM2304 is variably $\mathrm{Nod}^{+}$, but always Fix- $[5,6,30]$. Under conditions of competitive nodulation, WSM2304 may preferentially nodulate $T$. polymorphum even when outnumbered 100:1 by WSM1325 [7].

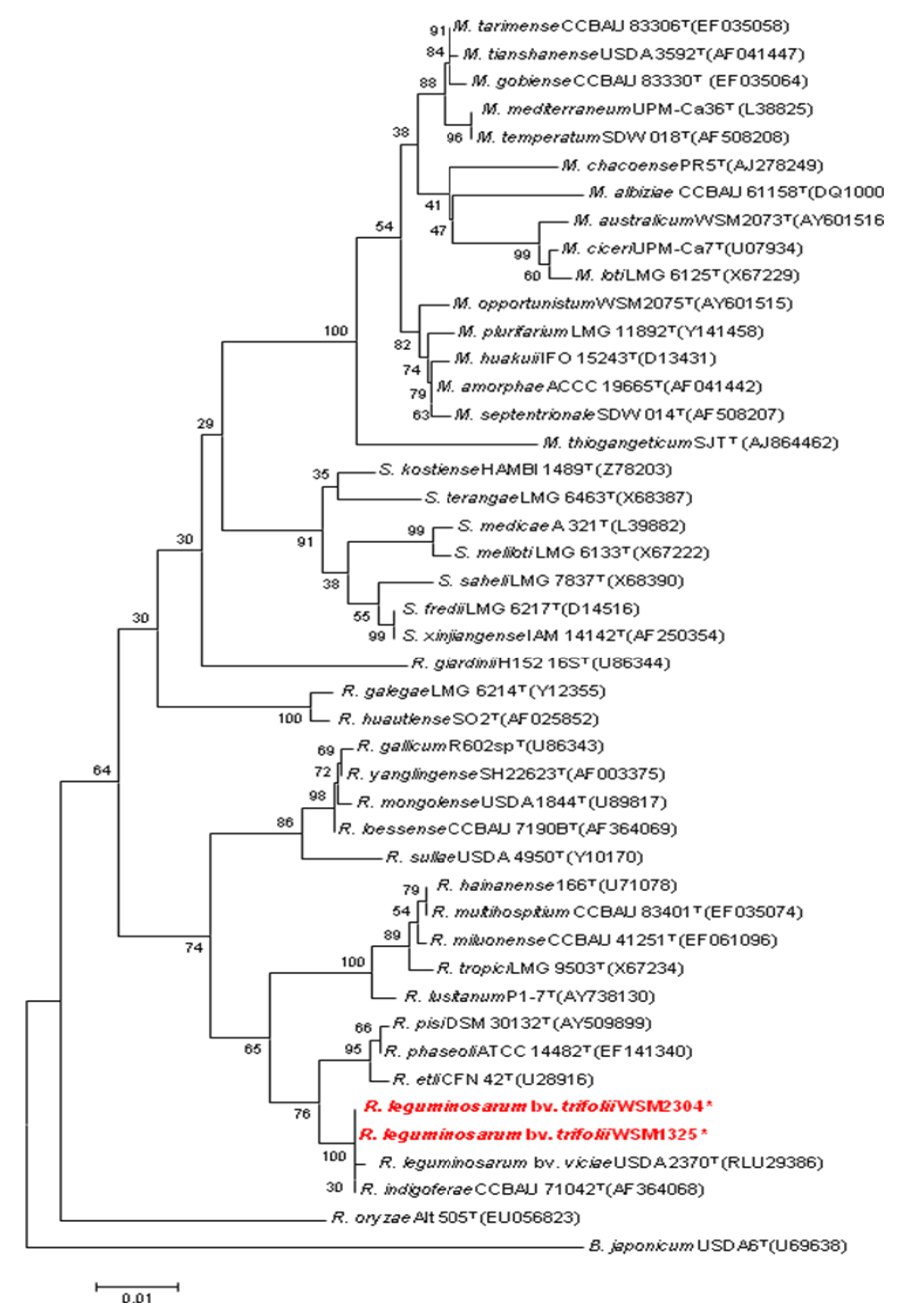

Figure 2. Phylogenetic tree showing the relationships of $R$. leguminosarum bv trifolii strain WSM2304 with the type strains of Rhizobiaceae based on aligned sequences of the $16 \mathrm{~S}$ rRNA gene $(1,440 \mathrm{bp}$ internal region). All sites were informative and there were no gap-containing sites. Phylogenetic analyses were performed using MEGA, version 3.1 [25]. Kimura two-parameter distances were derived from the aligned sequences [26] and a bootstrap analysis [27] as performed with 500 replicates in order to construct a consensus unrooted tree using the neighbor-joining method [28] for each gene alignment separately. The genera in this tree include Bradyrhizobium (B.), Mesorhizobium (M), Rhizobium (R); Ensifer (Sinorhizobium) (S). Type strains are indicated with a superscript T. Strains with a genome sequencing project registered in GOLD [22] are in bold red print. Published genomes are designated with an asterisk. 
Table 1. Classification and general features of $R$. leguminosarum bv trifolii WSM2304 according to the MIGS recommendations [8].

\begin{tabular}{|c|c|c|c|}
\hline MIGS ID & Property & Term & Evidence code \\
\hline & & Domain Bacteria & TAS $[5-7,9]$ \\
\hline & & Phylum Proteobacteria & TAS $[5-7,10]$ \\
\hline & & Class Alphaproteobacteria & TAS $[5-7,11,12]$ \\
\hline & & Order Rhizobiales & TAS $[5-7,11,13]$ \\
\hline & & Family Rhizobiaceae & TAS $[5-7,14]$ \\
\hline & & Genus Rhizobium & TAS $[5-7,14-18]$ \\
\hline & Classification & $\begin{array}{l}\text { Species Rhizobium leguminosarum bv trifolii } \\
\text { Strain WSM2304 }\end{array}$ & TAS $[5-7,14,16,18,19]$ \\
\hline & Gram stain & negative & TAS [20] \\
\hline & Cell shape & rod & TAS [20] \\
\hline & Motility & motile & TAS [20] \\
\hline & Sporulation & non-sporulating & TAS [20] \\
\hline & Temperature range & mesophile & TAS [20] \\
\hline & Optimum temperature & $28^{\circ} \mathrm{C}$ & TAS [20] \\
\hline & Salinity & unknown & TAS [20] \\
\hline \multirow[t]{3}{*}{ MIGS-22 } & Oxygen requirement & aerobic & TAS [20] \\
\hline & Carbon source & glucose, mannitol & TAS [5-7] \\
\hline & Energy source & chemoheterotroph & TAS [20] \\
\hline MIGS-6 & Habitat & Soil, root nodule, host & TAS [5-7] \\
\hline MIGS-15 & Biotic relationship & Free living, Symbiotic & TAS [5-7] \\
\hline \multirow[t]{3}{*}{ MIGS-14 } & Pathogenicity & none & TAS $[20]$ \\
\hline & Biosafety level & 1 & TAS [21] \\
\hline & Isolation & Trifolium polymorphum root nodule & TAS [22] \\
\hline MIGS-4 & Geographic location & Glencoe Research Station, INIA, Uruguay & TAS [22] \\
\hline MIGS-5 & Sample collection time & December $1^{\text {st }}, 1998$ & TAS [22] \\
\hline MIGS-4.1 & Latitude & -56 & \\
\hline MIGS-4.2 & Longitude & -31.41 & TAS [22] \\
\hline MIGS-4.3 & Depth & $5 \mathrm{~cm}$ soil depth & NAS [2] \\
\hline MIGS-4.4 & Altitude & $130 \mathrm{~m}$ & TAS [22] \\
\hline
\end{tabular}

Evidence codes - IDA: Inferred from Direct Assay (first time in publication); TAS: Traceable Author Statement (i.e., a direct report exists in the literature); NAS: Non-traceable Author Statement (i.e., not directly observed for the living, isolated sample, but based on a generally accepted property for the species, or anecdotal evidence). These evidence codes are from the Gene Ontology project [23]. If the evidence code is IDA, then the property was directly observed for a living isolate by one of the authors or an expert mentioned in the acknowledgements.

\section{Genome sequencing and annotation Genome project history}

This organism was selected for sequencing on the basis of its environmental and agricultural relevance to issues in global carbon cycling, alternative energy production, and biogeochemical importance, and is part of the Community Sequencing Program at the Department of Energy Joint Genome Institute (JGI) for projects of relevance to DOE missions. The genome project is deposited in the Genomes OnLine Database [22] and the complete genome sequence in GenBank. Sequencing, finishing and annotation were performed by the DOE Joint Genome Institute (JGI). A summary of the project information is shown in Table 2 and sequence data statistics from the trace archive for this project are presented in Table 3. 
Table 2. Genome sequencing project information for $R$. leguminosarum bv trifolii WSM2304.

\begin{tabular}{|c|c|c|}
\hline MIGS ID & Property & Term \\
\hline MIGS-31 & Finishing quality & Finished \\
\hline MIGS-28 & Libraries used & $\begin{array}{l}\text { Four genomic libraries: three Sanger libraries; } \\
\text { 1-2 kb pTH1522, 6-8 kb pMCL200, } \\
\text { fosmid pcc1Fos and one } 454 \text { pyrosequencing } \\
\text { standard library }\end{array}$ \\
\hline MIGS-29 & Sequencing platforms & ABI3730xI, 454 GS FLX \\
\hline MIGS-31.2 & Sequencing coverage & 21.3x Sanger; $10.1 x$ pyrosequencing \\
\hline MIGS-30 & Assemblers & Newbler version 1.1.02.15, Phrap \\
\hline \multirow[t]{11}{*}{ MIGS-32 } & Gene calling method & Prodigal \\
\hline & & CP001191 (Chromosome) ${ }^{\mathrm{a}}$ \\
\hline & & CP001192 (pRLG201) \\
\hline & Genbank ID & CP001193 (pRLG202) ${ }^{\mathrm{C}}$ \\
\hline & & CP001194 (pRLG204) ${ }^{d}$ \\
\hline & & CP001195 (pRLG205) ${ }^{\mathrm{e}}$ \\
\hline & Genbank Date of Release & October 16, 2008 \\
\hline & GOLD ID & Gc00870 \\
\hline & NCBI project ID & 20179 \\
\hline & Database: IMG & $643348569^{g}$ \\
\hline & Project relevance & Symbiotic nitrogen fixation, agriculture \\
\hline \multicolumn{3}{|c|}{ http://www.ncbi.nlm.nih.gov/nuccore/209533368 } \\
\hline \multicolumn{3}{|c|}{ http://www.ncbi.nlm.nih.gov/nuccore/209537694 } \\
\hline \multicolumn{3}{|c|}{ http://www.ncbi.nlm.nih.gov/nuccore/209538856 } \\
\hline \multicolumn{3}{|c|}{ http://www.ncbi.nlm.nih.gov/nuccore/209539307 } \\
\hline \multicolumn{3}{|c|}{ e http://www.ncbi.nlm.nih.gov/nuccore/209539531 } \\
\hline nttp://genome & /GOLD_CARDS/GC00870 & $\mathrm{tml}$ \\
\hline
\end{tabular}

\section{Growth conditions and DNA isolation}

R. leguminosarum bv trifolii WSM2304 was grown to mid logarithmic phase in TY medium (a rich medium) [31] on a gyratory shaker at $28^{\circ} \mathrm{C}$. DNA was isolated from $60 \mathrm{ml}$ of cells using a CTAB (Cetyl trimethylammonium bromide) bacterial genomic DNA isolation method (http://my.jgi.doe.gov).

\section{Genome sequencing and assembly}

The genome was sequenced using a combination of Sanger and 454 sequencing platforms. All general aspects of library construction and sequencing performed at the JGI can be found at the JGI website (http://www.jgi.doe.gov/). 454 Pyrosequencing reads were assembled using the Newbler assembler version 1.1.02.15 (Roche). Large Newbler contigs were broken into 5,676 fragments of $1,500 \mathrm{bp}$ with $100 \mathrm{bp}$ overlap and entered into the assembly as pseudo-reads. The se- quences were assigned quality scores based on Newbler consensus q-scores with modifications to account for overlap redundancy and to adjust inflated q-scores. A hybrid 454/Sanger assembly was made using the phrap assembler. Possible mis-assemblies were corrected and gaps between contigs were closed by custom primer walks from sub-clones or PCR products. A total of 1,826 Sanger finishing reads were produced. Illumina reads were used to improve the final consensus quality using an in-house developed tool (the Polisher). The final assembly consists of 168,617 Sanger reads in addition to 5,663 454 pseudo reads. The error rate of the completed genome sequence is less than 1 in 100,000. Together all sequence types provided about $31.4 \times$ coverage of the genome. 
Table 3. Production sequence for the finished genome of $R$. leguminosarum bv trifolii WSM2304, JGI project 4024175

\begin{tabular}{llcccc}
\hline Vector/Type & Library id & Insert size $\mathbf{( k b )}$ & Reads & Mb & q20 (Mb) \\
\hline pMCL200 & FHOO & $7.0 \pm 0.9$ & 74,398 & 66.6 & 51.6 \\
pcc1Fos & FHTU & $36 \pm 3.4$ & 15,776 & 11.8 & 7.8 \\
pTH1522 & FNNZ & $1.8 \pm 0.3$ & 79,386 & 68.6 & 53.5 \\
454-std & FHTW & NA & 719,338 & 69.9 & NA \\
\hline
\end{tabular}

\section{Genome annotation}

Genes were identified using Prodigal [32] as part of the Oak Ridge National Laboratory genome annotation pipeline, followed by a round of manual curation using the JGI GenePRIMP pipeline [33]. The predicted CDSs were translated and used to search the National Center for Biotechnology Information (NCBI) nonredundant database, UniProt, TIGRFam, Pfam, PRIAM, KEGG, COG, and InterPro databases. Additional gene prediction analyses and functional annotation were performed within the Integrated Microbial Genomes platform (http://img.jgi.doe.gov/er) [34].

\section{Genome properties}

The genome is 6,872,702 bp long with a $61.18 \%$ GC content, (Table 4) and comprised of 5 replicons; 1 circular chromosome of size 4,537,948 bp (Figure 3 ) and 4 circular plasmids of size 4,537,948, 1,266,105, 501,946, 308,747 and 257,956 bp (Figure 4). Of the 6,643 genes predicted, 6,581 were protein coding genes, and 62 RNA only encoding genes. In addition, 166 pseudogenes were identified. The majority of the genes (72.44\%) were assigned a putative function whilst the remaining ones were annotated as hypothetical proteins. The distribution of genes into COGs functional categories is presented in Table 5.

Table 4. Genome Statistics for R. leguminosarum bv trifolii WSM2304

\begin{tabular}{lrr}
\hline Attribute & Value & \% of Total \\
\hline Genome size (bp) & $6,872,702$ & $100.00 \%$ \\
DNA coding region (bp) & $6,053,973$ & $88.09 \%$ \\
DNA G+C content (bp) & $4,204,577$ & $61.18 \%$ \\
Number of replicons & 5 & $100.00 \%$ \\
Extrachromosomal elements & 4 & $80.00 \%$ \\
Total genes & 6,643 & $100.00 \%$ \\
RNA coding genes & 62 & $0.93 \%$ \\
rRNA operons & 3 & \\
Protein-coding genes & 6,581 & $99.07 \%$ \\
Pseudo genes & 166 & $2.49 \%$ \\
Genes with function prediction & 4,812 & $72.44 \%$ \\
Genes in paralog clusters & 4,104 & $61.78 \%$ \\
Genes assigned to COGs & 5,105 & $76.85 \%$ \\
Genes assigned Pfam domains & 5,149 & $77.51 \%$ \\
Genes with signal peptides & 2,247 & $33.83 \%$ \\
Genes with transmembrane helices & 1,495 & $22.50 \%$ \\
CRISPR repeats & 0 & \\
\hline
\end{tabular}




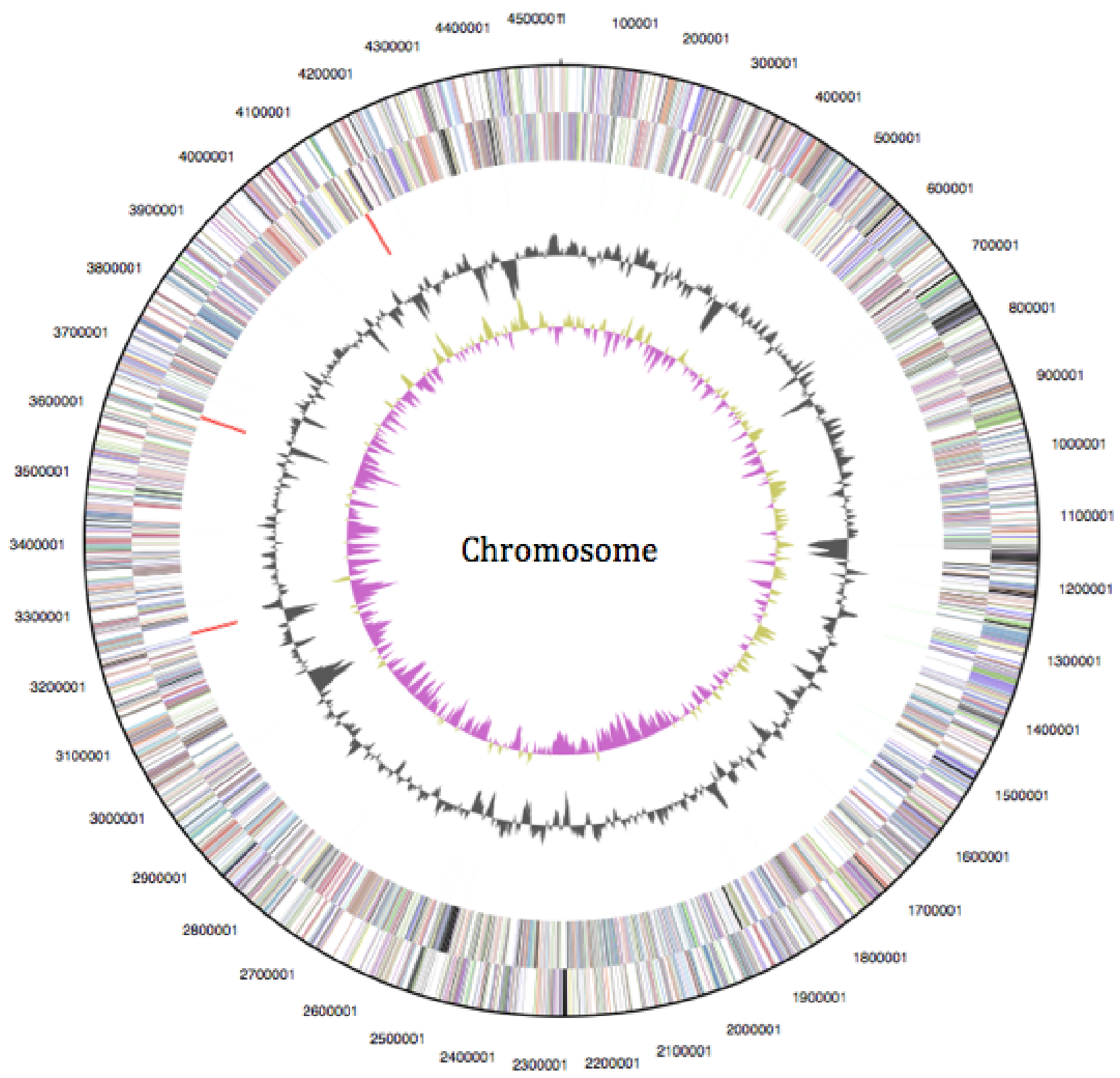

Figure 3. Graphical circular map of the chromosome of $R$. leguminosarum bv trifolii WSM2304. From outside to the center: Genes on forward strand (color by COG categories as denoted by the IMG platform), Genes on reverse strand (color by COG categories), RNA genes (tRNAs green, sRNAs red, other RNAs black), GC content, GC skew. Chromosome is not drawn to scale relative to the plasmids in Figure 4. 

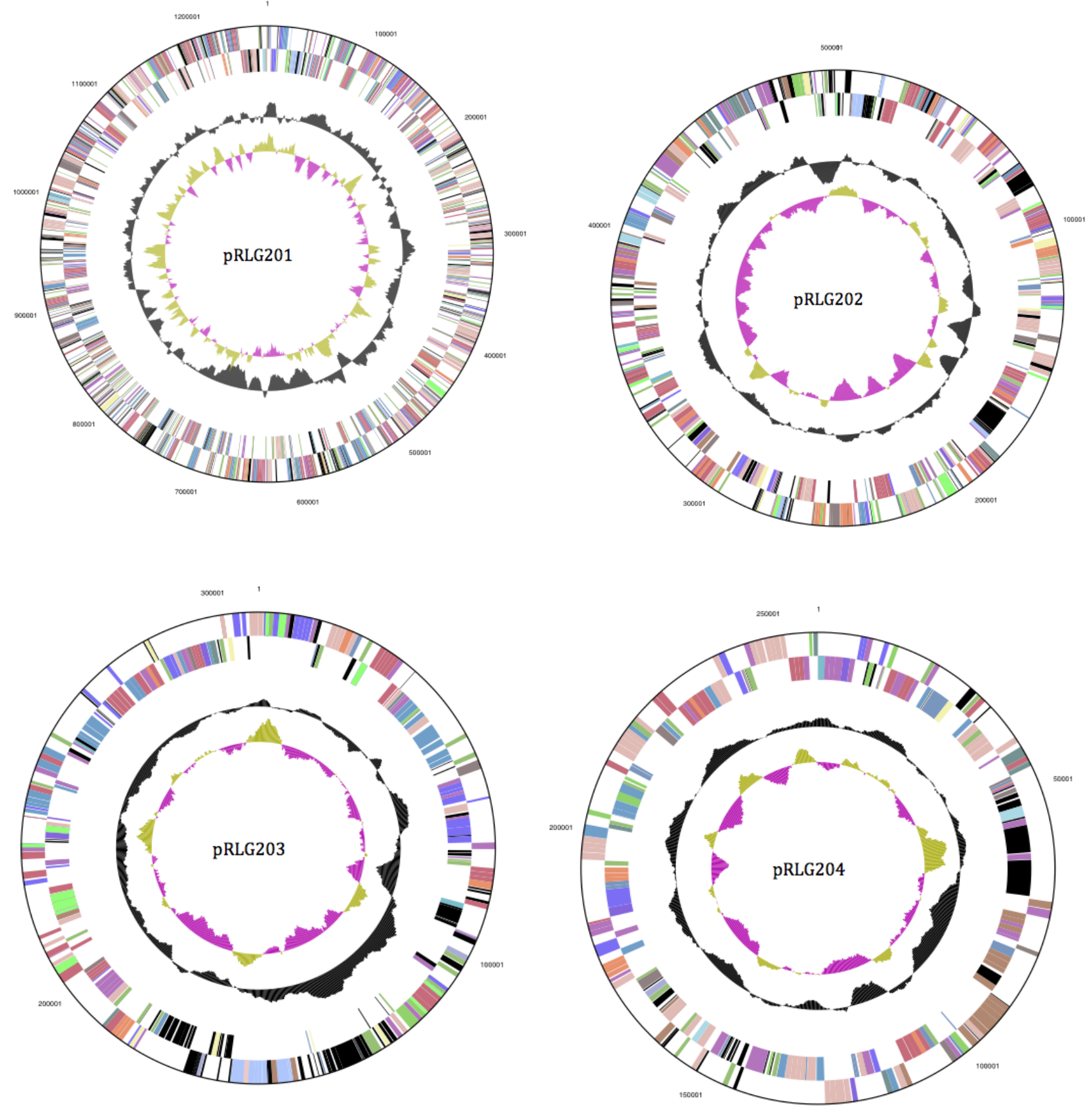

Figure 4. Graphical circular map of the plasmids of $R$. leguminosarum bv trifolii WSM2304. From outside to the center: Genes on forward strand (color by COG categories as denoted by the IMG platform), Genes on reverse strand (color by COG categories), RNA genes (tRNAs green, sRNAs red, other RNAs black), GC content, GC skew. Plasmids pRLG201, pRLG202, pRLG203 and pRLG204 are not drawn to scale relative to each other or to the chromosome in Figure 3. 
Table 5. Number of genes associated with the general COG functional categories

\begin{tabular}{lrrl}
\hline Code & value & \%age & Description \\
\hline J & 194 & 2.95 & Translation, ribosomal structure and biogenesis \\
A & 0 & 0.00 & RNA processing and modification \\
K & 558 & 8.48 & Transcription \\
L & 164 & 2.49 & Replication, recombination and repair \\
B & 2 & 0.03 & Chromatin structure and dynamics \\
D & 38 & 0.58 & Cell cycle control, mitosis and meiosis \\
Y & 0 & 0.00 & Nuclear structure \\
V & 66 & 1.00 & Defense mechanisms \\
T & 317 & 4.82 & Signal transduction mechanisms \\
M & 309 & 4.70 & Cell wall/membrane biogenesis \\
N & 91 & 1.38 & Cell motility \\
Z & 0 & 0.00 & Cytoskeleton \\
W & 0 & 0.00 & Extracellular structures \\
U & 88 & 1.34 & Intracellular trafficking and secretion \\
O & 165 & 2.51 & Posttranslational modification, protein turnover, chaperones \\
C & 314 & 4.77 & Energy production and conversion \\
G & 599 & 9.10 & Carbohydrate transport and metabolism \\
E & 687 & 10.44 & Amino acid transport and metabolism \\
F & 109 & 1.66 & Nucleotide transport and metabolism \\
H & 180 & 2.74 & Coenzyme transport and metabolism \\
I & 238 & 3.62 & Lipid transport and metabolism \\
P & 278 & 4.22 & Inorganic ion transport and metabolism \\
Q & 156 & 2.37 & Secondary metabolites biosynthesis, transport and catabolism \\
R & 710 & 10.79 & General function prediction only \\
S & 532 & 8.08 & Function unknown \\
- & 1,476 & 22.43 & Not in COGs \\
\hline
\end{tabular}

\section{Acknowledgements}

This work was performed under the auspices of the US Department of Energy's Office of Science, Biological and Environmental Research Program, and by the University of California, Lawrence Berkeley National Laboratory under contract No. DE-AC02-05CH11231, Lawrence Livermore National Laboratory under Contract No. DEAC52-07NA27344, and Los Alamos National Laboratory under contract No. DE-AC02-06NA25396. We thank

\section{References}

1. Hamblin J. Preface, 1998, pp xi-xiii. In: Lupins as Crop Plants. Biology, Production and Utilization. Gladstones JS, Atkins CA, Hamblin J (Eds.). CAB International, Madison, NY.

2. Sprent JI. Legume nodulation: a global perspective. 2009. Oxford, Wiley-Blackwell.
Gordon Thompson (Murdoch University) for the preparation of SEM and TEM photos. We gratefully acknowledge the funding received from Murdoch University Strategic Research Fund through the Crop and Plant Research Institute (CaPRI), and the Grains Research and Development Corporation (GRDC), to support the National Rhizobium Program (NRP) and the Centre for Rhizobium Studies (CRS) at Murdoch University.

3. Herridge DF, Peoples MB, Boddey RM. Global inputs of biological nitrogen fixation in agricultural systems. Marschner Review. Plant Soil 2008; 311:1-18. doi:10.1007/s11104-008-9668-3

4. Zohary M, Heller D. The Genus Trifolium. The Israel Academy of Sciences and Humanities, Ahva Printing Press 1984, Jerusalem. 
Reeve et al.

5. Howieson JG, Yates RJ, O'Hara GW, Ryder M, Real D. The interactions of Rhizobium leguminosarum biovar trifolii in nodulation of annual and perennial Trifolium spp from diverse centres of origin. Aust J Exp Agric 2005; 45:199-

207. doi:10.1071/EA03167

6. Yates RJ, Howieson JG, Real D, Reeve WG, Vivas-Marfisi A, O'Hara GW. Evidence of selection for effective nodulation in the Trifolium spp. symbiosis with Rhizobium leguminosarum biovar trifolii. Aust J Exp Agric 2005; 45:189-

198. doi:10.1071/EA03168

7. Yates RJ, Howieson JG, Reeve WG, Brau L, Speijers J, Nandasena K, Real D, Sezmis E, O'Hara GW. Host-strain mediated selection for an effective nitrogen-fixing symbiosis between Trifolium spp. and Rhizobium leguminosarum biovar trifolii. Soil Biol Biochem 2008; 40:822-

833. doi:10.1016/j.soilbio.2007.11.001

8. Field D, Garrity G, Gray T, Morrison N, Selengut J, Sterk P, Tatusova T, Thomson N, Allen MJ, Angiuoli SV. Towards a richer description of our complete collection of genomes and metagenomes: the "Minimum Information about a Genome Sequence" (MIGS) specification. Nat Biotechnol 2008; 26:541-547.

PubMed doi:10.1038/nbt1360

9. Woese CR, Kandler O, Wheelis ML. Towards a natural system of organisms: proposal for the domains Archaea, Bacteria, and Eucarya. Proc Natl Acad Sci USA 1990; 87: 4576-4579.

PubMed doi:10.1073/pnas.87.12.4576

10. Garrity GM, Holt JG. The Road Map to the Manual. In: Garrity GM, Boone DR, Castenholz RW (eds), Bergey's Manual of Systematic Bacteriology, Second Edition, Volume 1, Springer, New York, 2001, p. 119-169.

11. Garrity GM, Bell JA, Lilburn T. Class I. Alphaproteobacteria class. nov. In: Garrity GM, Brenner DJ, Krieg NR, Staley JT (eds), Bergey's Manual of Systematic Bacteriology, Second Edition, Volume 2, Part C, Springer, New York, 2005, p. 1.

12. List editor. Validation List No. 107. List of new names and new combinations previously effectively, but not validly, published. Int I Syst Evol Microbiol 2006; 56: 1-6.

PubMed doi:10.1099/ijs.0.64188-0

13. Kuykendall LD. Order VI. Rhizobiales ord. nov. In: Garrity GM, Brenner DJ, Krieg NR, Staley JT (eds), Bergey's Manual of Systematic Bacteriology, Second Edition, Volume 2, Part C, Springer, New York, 2005, p. 324.
14. Skerman VBD, McGowan V, Sneath PHA. Approved Lists of Bacterial Names. Int / Syst Bacteriol 1980; 30: 225-420.

15. Frank B. Über die Pilzsymbiose der Leguminosen. Ber Dtsch Bot Ges 1889; 7: 332-346.

16. Jordan DC, Allen ON. Genus I. Rhizobium Frank 1889, 338; Nom. gen. cons. Opin. 34, Jud.

Comm. 1970, 11. In: Buchanan RE, Gibbons NE (eds), Bergey's Manual of Determinative Bacteriology, Eighth Edition, The Williams and Wilkins Co., Baltimore, 1974, p. 262-264.

17. Young JM, Kuykendall LD, Martínez-Romero E, Kerr A, Sawada H. A revision of Rhizobium Frank 1889 , with an emended description of the genus, and the inclusion of all species of Agrobacterium Conn 1942 and Allorhizobium undicola de Lajudie et al. 1998 as new combinations: Rhizobium radiobacter, $R$. rhizogenes, $R$. rubi, $R$. undicola and R. vitis.. Int J Syst Evol Microbiol 2001; 51: 89-103. PubMed

18. Editorial Secretary (for the Judicial Commission of the International Committee on Nomenclature of Bacteria). OPINION 34: Conservation of the Generic Name Rhizobium Frank 1889. Int / Syst Bacteriol 1970; 20: 11-12; doi:10.1099/0020771320-1-11.

19. Ramírez-Bahena MH, García-Fraile P, Peix A, Valverde A, Rivas R, Igual JM, Mateos PF, Martínez-Molina E, Velázquez E. Revision of the taxonomic status of the species Rhizobium leguminosarum (Frank 1879) Frank 1889 ${ }^{\mathrm{AL}}$, Rhizobium phaseoli Dangeard 1926AL and Rhizobium trifolii Dangeard 1926AL. $R$. trifolii is a later synonym of $R$. leguminosarum. Reclassification of the strain $R$. leguminosarum DSM 30132 (=NCIMB 11478) as Rhizobium pisi sp. nov.. Int I Syst Evol Microbiol 2008; 58: 2484-2490. PubMed doi:10.1099/ijs.0.65621-0

20. Kuykendall LD, Hashem F, Wang ET. Genus VII. Rhizobium, 2005, pp 325-340. In: Bergey's Manual of Systematic Bacteriology. Second Edition. Volume 2 The Proteobacteria. Part C The Alpha-, Delta-, and Epsilonproteobacteria. Brenner DJ, Krieg NR, Staley JT (Eds.), Garrity GM (Editor in Chief) Springer Science and Business Media Inc, New York, USA.

21. Biological Agents. Technical rules for biological agents www.baua.de TRBA 466.

22. Liolios K, Mavromatis K, Tavernarakis N, Kyrpides NC. The Genomes OnLine Database (GOLD) in 2007: status of genomic and metagenomic projects and their associated metadata. Nucleic 
Acids Res 2008; 36:D475-D479.

PubMed doi:10.1093/nar/gkm884

23. Ashburner M, Ball CA, Blake JA, Botstein D, Butler $\mathrm{H}$, Cherry JM, Davis AP, Dolinski K, Dwight SS, Eppig JT, et al. The Gene Ontology Consortium. Gene ontology: tool for the unification of biology. Nat Genet 2000; 25:25-29.

PubMed doi:10.1038/75556

24. Howieson JG, Ewing MA, D'Antuono MF. Selection for acid tolerance in Rhizobium meliloti.

Plant Soil 1988; 105:179-

188. doi:10.1007/BF02376781

25. Kumar S, Tamura K, Nei M. MEGA3: integrated software for molecular evolutionary genetics analysis and sequence alignment. Brief Bioinform 2004; 5:150-163. PubMed

PubMed doi:10.1093/bib/5.2.150

26. Kimura M. A simple model for estimating evolutionary rates of base substitutions through comparative studies of nucleotide sequences. / Mol Evol 1980; 16:111-120. PubMed doi:10.1007/BF01731581

27. Felsenstein J. Confidence limits on phylogenies: an approach using the bootstrap. Evolution 1985; 39:783-791. doi:10.2307/2408678

28. Saitou N, Nei M. Reconstructing phylogenetic trees. Mol Biol Evol 1987; 4:406-425. PubMed
29. Bullard GK, Roughley RJ, Pulsford DJ. The legume inoculant industry and inoculant quality control in Australia: 1953-2003. Aust J Exp Agric 2005; 45:127-140. doi:10.1071/EA03159

30. Centre for. Rhizobium Studies. Annual Report. JG Howieson (Ed). 2001. Murdoch University Print, Perth, Australia.

31. Reeve WG, Tiwari RP, Worsely PS, Dilworth MJ, Glenn AR, Howieson JG. Constructs for insertional mutagenesis, transcriptional signal localization and gene regulation studies in root nodule and other bacteria. Microbiology 1999; 145:13071316. PubMed doi:10.1099/13500872-145-6$\underline{1307}$

32. Anonymous. Prodigal Prokaryotic Dynamic Programming Genefinding Algorithm. Oak Ridge National Laboratory and University of Tennessee 2009. http://compbio.ornl.gov/prodigal

33. Pati A, Ivanova N, Mikhailova N, Ovchinikova G, Hooper SD, Lykidis A, Kyrpides NC. GenePRIMP: A Gene Prediction Improvement Pipeline for microbial genomes. (Submitted) 2009

34. Markowitz VM, Szeto E, Palaniappan K, Grechkin Y, Chu K, Chen IMA, Dubchak I, Anderson I, Lykidis A, Mavromatis K, et al. The Integrated Microbial Genomes (IMG) system in 2007: data content and analysis tool extensions. Nucleic Acids Res 2008; 36:D528-D533. PubMed doi:10.1093/nar/gkm846 